\title{
Role of micronised progesterone in maintenance therapy following arrested preterm labor: a randomised controlled trial
}

\author{
Gitika Shankar Mishra*, S. A. Inamdar
}

Department of Obstetrics \& Gynaecology, Datta Meghe Institute of Medical Sciences, Sawangi, Wardha, MH, India

Received: 17 October 2014

Accepted: 1 November 2014

\section{*Correspondence:}

Dr. Gitika Shankar Mishra,

E-mail: gitikashankar@gmail.com

Copyright: (c) the author(s), publisher and licensee Medip Academy. This is an open-access article distributed under the terms of the Creative Commons Attribution Non-Commercial License, which permits unrestricted non-commercial use, distribution, and reproduction in any medium, provided the original work is properly cited.

\begin{abstract}
Background: The aims and objectives of this study were to determine whether maintenance tocolytic therapy with micronised progesterone $(400 \mathrm{mg}$ ) in patients with arrested preterm labor, prolongs the latency period of gestation and to see the effect of prolonged latency period on fetal outcome in terms of birth weight and NICU admissions and maternal outcome in terms of prolongation to term gestation.

Methods: Pregnant women who were arrested with acute tocolysis as evidenced by a 12 hour contraction free period were randomized into study and control groups. The study group received $400 \mathrm{mg}$ of vaginal micronized progesterone daily, while the control group did not receive any drug. The patients were followed up till 37 completed weeks. Prolongation of pregnancy upto term and birth wt. and NICU admissions were noted.

Results: 1) In the present study the mean period of gestation at delivery was significantly high in study group $37.51 \pm$ 2.70 weeks as compared to that in control group $35.15 \pm 2.72$ weeks. This was statistically significant at $95 \%$ confidence interval by using student's t statistics. 2) In the present study, $42.00 \%$ babies in study group had birth weight more than $2.5 \mathrm{~kg}$ which was significantly higher than that in control group, in which $24.00 \%$ had birth weight more than $2.5 \mathrm{~kg}$.

Conclusions: We conclude that, maintenance tocolytic therapy with micronised progesterone (400 mg) up-to 37 weeks of gestation in patients with arrested preterm labor significantly prolongs the latency period and results in better perinatal outcome
\end{abstract}

Keywords: Preterm labor, Birth weight, Latency period, NICU admissions

\section{INTRODUCTION}

Preterm birth is the most frequent cause of fetal and neonatal morbidity and mortality. ${ }^{2}$ The incidence of preterm birth is variably reported between $5 \%-11 \%$ of all births. ${ }^{1}$ Preterm labor is defined by WHO as the occurrence of labor in women with gestational age between 20-37 weeks. ${ }^{11}$ Preterm delivery continues to provide an enormous challenge in the delivery of perinatal health care, which is estimated to affect approximately 13 million births annually worldwide. ${ }^{3}$
Incidence of preterm labor is $23.3 \%$ and preterm delivery is $10-69 \%$ in India. ${ }^{11}$ Prematurity contributes to $75 \%$ of all neonatal deaths and $50 \%$ of long term neurological neonatal morbidity. ${ }^{5}$ India is among the 10 countries with highest number of preterm birth. ${ }^{4}$

Preterm labor was defined as regular uterine contractions 4 times in 20 minutes or 8 times in 60 minutes with progressive cervical dilatation greater than $1 \mathrm{~cm}$ and effacement at least $80 \%{ }^{15}$ 
Arrested preterm is defined as a 12 hour contraction free period after tocolysis has been discontinued. ${ }^{6}$

Latency period is the number of days of pregnancy gained after arresting preterm labor till delivery.

The effectiveness of tocolysis in patients with preterm labor to stop uterine contractions (acute tocolysis) or maintain quiescence (maintenance therapy) has been reviewed in past. The primary therapeutic goal of acute tocolysis is to delay preterm delivery long enough upto 48 hours from initiation of steroid prophylaxis. Many drugs have been used for this purpose viz. isoxsuprine hydrochloride, nifedipine, magnesium sulphate, beta mimetics, indomethacin, atosiban, etc. These drugs have been further tested for maintenance tocolysis. However, long term use of these drugs was observed to have less efficacy and also adverse effects, due to which they are not recommended for maintenance. , $, 7,8,13,14^{-1}$

On the other hand, progesterone has long been considered an important agent in the maintenance of uterine quiescence and has been used extensively in primary and secondary prevention of preterm delivery. Progesterone helps in allowing pregnancy to reach its physiologic term because at sufficient levels in the myometrium, it blocks the oxytocic effect of prostaglandin F2 alpha. ${ }^{6}$

Natural progesterone is free of any disturbing teratogenic, metabolic or haemodynamic side effects. However, this is not true for certain artificial progestins. A vaginal pessary of micronized natural progesterone was preferred over intramuscular synthetic progesterone because of enhanced bioavailability and absence of undesirable side effects such as fatigue, drowsiness and headache. We therefore, chose this pharmacological agent as drug for our study. ${ }^{6}$

Progesterone, which is present in high concentrations during pregnancy, increases cAMP production. cAMP and cGMP maintain uterine quiescence by promoting the uptake of intracellular calcium into the sarcoplasmic reticulum and thereby reducing intracellular calcium concentrations and reducing contractility. They also lower the amount of phosphorylated myosin and promote myometrial relaxation. Progesterone therefore exerts a relaxant effect on the uterus, and has been used in the treatment of preterm labor. ${ }^{7}$ Progesterone decreases contractility of uterine smooth muscle. ${ }^{12}$

Natural progesterone has been used in pregnancy without demonstrable effect on fetal development or on the risk of congenital anomalies. ${ }^{9,10}$

Natural progesterone is free of any disturbing teratogenic, metabolic, or hemodynamic effects. The maternal side effects related to progesterone therapy include headache, nausea, breast tenderness and cough, which are however found to be rare. ${ }^{9,10}$

\section{METHODS}

It was a randomised control trial carried out in department of obstetrics and gynaecology, Acharya Vinoba Bhave rural hospital, Sawangi, Wardha, Maharashtra from 2012-2014. Patients with preterm labor were arrested with acute tocolysis by tab. Isoxsuprine hydrochloride thrice a day for three days, women who had 12 hour contraction free period after stopping acute tocolysis were labelled as patients with arrested preterm labor. During this period 100 pregnant women with arrested preterm labor who fulfilled inclusion criteria were included in study and divided into two groups study group and control group. Study group received $400 \mathrm{mg}$ of micronised progesterone daily and control group did not receive any drug. Both were followed till term and prolongation of period of gestation, birth weight and need for NICU admissions were noted.

\section{Selection criteria}

\section{Inclusion criteria}

1. Singleton pregnancy.

2. Gestational age between 28 to 36 completed weeks.

3. Patients with confirmed gestational age by LMP and/or first or second trimester ultrasound scan.

4. Preterm labor arrested which was with isoxsuprine hydrochloride tocolytic regimen.

\section{Exclusion criteria}

1. Preterm premature rupture of membranes.

2. Cervical encerclage.

3. Chorioamnionitis

4. Multiple gestation

\section{RESULTS}

In the present study majority of the patients were in the age group of 21 to 25 years and the distribution was comparable in both the study and control groups $(50.00 \%$ vs. $60.00 \%$ ) (Table 1$)$.

\section{Table 1: Age wise distribution of women.}

\begin{tabular}{|lllll|}
\hline \multirow{2}{*}{$\begin{array}{l}\text { Age group } \\
\text { (years) }\end{array}$} & \multicolumn{2}{l}{ Study group } & \multicolumn{2}{c|}{ Control group } \\
\hline$<21$ & 16 & 32.00 & 6 & 12.00 \\
\hline $21-25$ & 25 & 50.00 & 30 & 60.00 \\
\hline $26-29$ & 6 & 12.00 & 6 & 12.00 \\
\hline $30-34$ & 3 & 6.00 & 6 & 12.00 \\
\hline$>34$ & 0 & 0.00 & 2 & 4.00 \\
\hline Total & 50 & 100.00 & 50 & 100.00 \\
\hline
\end{tabular}

In the present study the mean age in study group was 25.1 \pm 3.77 years whereas in control group mean age was 24.1 \pm 2.93 years which was comparable (Table 2 ). 
Table 2: Comparison of mean age and standard deviation.

\begin{tabular}{|lll|}
\hline Mean \pm SD & Study group & Control group \\
\hline Median & $25.1 \pm 3.77$ & $24.1 \pm 2.93$ \\
\hline Minimum & 19 & 24 \\
\hline Maximum & 37 & 19 \\
\hline
\end{tabular}

$\mathrm{t}=2.481 ; \mathrm{DF}=98 ; \mathrm{P}=0.030$

In the present study, the number of primigravida and multigravida were $34.00 \%$ and $66.00 \%$ in the study group respectively. While in control group primigravida and multi gravida were $44.00 \%$ and $56.00 \%$ respectively (Table 3).

Table 3: Parity.

\begin{tabular}{|lllll|}
\hline \multirow{2}{*}{ Parity } & \multicolumn{2}{c|}{ Study group } & \multicolumn{2}{c|}{ Control group } \\
& No. & \% & No. & \% \\
\hline Primi & 17 & 34.00 & 22 & 44.00 \\
\hline Multi & 33 & 66.00 & 28 & 56.00 \\
\hline Total & 50 & 100.00 & 50 & 100.00 \\
\hline
\end{tabular}

Chi square $=0.673 ; \mathrm{P}=0.412$

In the present study, out of 50 women $33(66.00 \%)$ were enrolled at 28 to 31.6 weeks, $11(22.00 \%)$ were enrolled at 32 to 33.6 weeks and $6(12.00 \%)$ were enrolled at 28 to 31.6 weeks each in the study group. In the control group, maximum numbers of women $(50.00 \%)$ were enrolled at 34 to 36.6 weeks, followed by $28.00 \%$ at 32 to 33.6 weeks followed by $22.00 \%$ at 28 to 31.6 weeks. The gestational age of the eligible women, at enrollment was comparable in both study and control groups $(\mathrm{P}=0.231)$ (Table 4).

Table 4: Period of gestation at enrollment.

\begin{tabular}{|c|c|c|c|c|}
\hline \multirow{2}{*}{$\begin{array}{l}\text { Period of } \\
\text { gestation } \\
\text { (weeks) }\end{array}$} & \multicolumn{2}{|c|}{ Study group } & \multicolumn{2}{|c|}{ Control group } \\
\hline & No. & $\%$ & No. & $\%$ \\
\hline $28-31.6$ & 6 & 12.00 & 11 & 22.00 \\
\hline $32-33.6$ & 11 & 22.00 & 14 & 28.00 \\
\hline $34-36.6$ & 33 & 66.00 & 25 & 50.00 \\
\hline Total & 50 & 100.00 & 50 & 100.00 \\
\hline
\end{tabular}

Chi square $=2.934 ; \mathrm{P}=0.231$

In the present study, in study group majority of women $26(52.00 \%)$ delivered between 37 to 40 weeks at the time of delivery as compared to $15(30.00 \%)$ in control group. Majority of the women in control group 21 $(42.00 \%)$ delivered between 34 to 36.6 weeks $(\mathrm{P}=0.042)$ (Table 5).

In the present study the mean period of gestation at delivery was significantly high in study group $37.51 \pm$
2.70 weeks as compared to that in control group $35.15 \pm$ 2.72 weeks. This was statistically significant at $95 \%$ confidence interval by using student's t statistics (Table $6)$.

Table 5: Period of gestation at delivery.

\begin{tabular}{|lllll|}
\hline $\begin{array}{l}\text { Period of } \\
\text { gestation } \\
\text { (weeks) }\end{array}$ & No. & $\%$ & No. & $\%$ \\
\hline $28-31.6$ & 2 & 4.00 & 8 & 16.00 \\
\hline $32-33.6$ & 2 & 4.00 & 5 & 10.00 \\
\hline $34-36.6$ & 13 & 26.00 & 21 & 42.00 \\
\hline $37-40$ & 26 & 52.00 & 15 & 30.00 \\
\hline$>40$ & 7 & 14.00 & 1 & 2.00 \\
\hline Total & 50 & 100.00 & 50 & 100.00 \\
\hline
\end{tabular}

Chi square $=3.766 ; \mathrm{P}=0.042$

Table 6: Comparison of mean period of gestation at delivery.

\begin{tabular}{|lll|}
\hline Mean \pm SD & Study group & Control group \\
\hline Median & $37.51 \pm 2.70$ & $35.15 \pm 2.72$ \\
\hline Minimum & 28.50 & 35.20 \\
\hline Maximum & 41.3 & 28.20 \\
\hline
\end{tabular}

$\mathrm{t}=4.354 ; \mathrm{DF}=98 ; \mathrm{P}=0.001$

In the present study maximum latency period beyond 36 days was noted in study group as compared to control group. Majority of women $11(22.00 \%)$ had latency period between 29 to 35 days as well as $11(22.00 \%)$ women had latency period between 36 to 42 days in study group. In control group, majority of the women 25 $(50.00 \%)$ had a latency period of less than 7 days. This difference between both the groups was statistically significant as $\mathrm{P}<0.05$ (Table 7).

Table 7: Latency period.

\begin{tabular}{|lllll|}
\hline $\begin{array}{l}\text { Latency } \\
\text { period } \\
\text { (days) }\end{array}$ & \multicolumn{2}{l}{ Study group } & \% & Control group \\
\hline Up to 7 & 8 & 16.00 & 25 & $\%$ \\
\hline $8-14$ & 6 & 12.00 & 6 & 12.00 \\
\hline $15-21$ & 5 & 10.00 & 11 & 22.00 \\
\hline $22-28$ & 5 & 10.00 & 5 & 10.00 \\
\hline $29-35$ & 11 & 22.00 & 3 & 6.00 \\
\hline $36-42$ & 11 & 22.00 & 0 & 0.00 \\
\hline$>42$ & 4 & 8.00 & 0 & 0.00 \\
\hline Total & 50 & 100.00 & 50 & 100.00 \\
\hline
\end{tabular}

$\mathrm{t}=5.743 ; \mathrm{DF}=98 ; \mathrm{P}=0.001$

The mean latency period in study group was $26.38 \pm$ 15.47 higher than that of control group $11.74 \pm 9.25$ in 
days. This was statistically significant at $95 \%$ confidence interval as $\mathrm{P}$ value $<0.05$ (Table 8 ).

Table 8: Mean latency period in days.

\begin{tabular}{|lll|}
\hline Latency period & Study group & Control group \\
\hline Mean \pm SD & $26.38 \pm 15.47$ & $11.74 \pm 9.25$ \\
\hline
\end{tabular}

$\mathrm{t}=5.743 ; \mathrm{DF}=98 ; \mathrm{P}=0.001$

In the present study the recurrence of preterm labor was significantly high in the control group as $68.00 \%$ of the mothers delivered before 37 weeks compared to only $44.00 \%$ mothers in the study group $\mathrm{p}$ value $<0.05$. This was statistically significant (Table 9).

Table 9: Recurrence of preterm labor.

\begin{tabular}{|lllll|}
\hline POG & \multicolumn{2}{c|}{ Study group } & \multicolumn{2}{c|}{ Control group } \\
(weeks) & No. & $\%$ & No. & \% \\
\hline$<37$ & 22 & 44.00 & 34 & 68.00 \\
\hline$>37$ & 28 & 56.00 & 16 & 32.00 \\
\hline Total & 50 & 100.00 & 50 & 100.00 \\
\hline
\end{tabular}

Chi square $=4.911 ; \mathrm{P}=0.027$

In the present study, 21 babies $(42.00 \%)$ in study group had birth weight more than $2.5 \mathrm{~kg}$ which was significantly higher than that in control group, in which only 12 babies $(24.00 \%)$ had birth weight more than 2.5 $\mathrm{kg}$ as $\mathrm{P}<0.05$ (Table 10).

Table 10: Birth weight.

\begin{tabular}{|lllll|}
$\begin{array}{l}\text { Birth } \\
\text { weight } \\
(\mathrm{kg})\end{array}$ & \multicolumn{2}{l}{ Study group } & $\boldsymbol{2}$ Control group \\
\hline$<1.5$ & 1 & 2.00 & $\mathbf{N}$ & $\mathbf{\%}$ \\
\hline $1.5-2.0$ & 12 & 24.00 & 12 & 8.00 \\
\hline $2.1-2.5$ & 16 & 32.00 & 21 & 42.00 \\
\hline $2.6-3.0$ & 18 & 36.00 & 11 & 22.00 \\
\hline $3.1-3.5$ & 2 & 4.00 & 2 & 4.00 \\
\hline$>3.5$ & 1 & 2.00 & 0 & 0.00 \\
\hline Total & 50 & 100.00 & 50 & 100.00 \\
\hline
\end{tabular}

The mean birth weight of babies in study group $2.39 \pm$ 0.44 was significantly higher than that in control group $2.20 \pm 0.49$ (Table 11).

Table 11: Comparison of mean birth weight.

\begin{tabular}{|lll|}
$\begin{array}{l}\text { Birth weight } \\
(\mathrm{kg})\end{array}$ & Study group & Control group \\
\hline Mean \pm SD & $2.39 \pm 0.44$ & $2.20 \pm 0.49$ \\
\hline
\end{tabular}

$$
\mathrm{t}=2.040 ; \mathrm{DF}=98 ; \mathrm{P}=0.04
$$

In the present study only 10 babies $(20.00 \%)$ from study group were admitted in NICU whereas in control group
$18(36.00 \%)$ babies were admitted in NICU. This difference was statistically significant as $\mathrm{P}<0.05$ (Table 12).

Table 12: NICU admission.

\begin{tabular}{|lllll|}
\hline \multirow{2}{*}{$\begin{array}{l}\text { NICU } \\
\text { admission }\end{array}$} & \multicolumn{2}{c|}{ Study group } & \multicolumn{2}{c|}{ Control group } \\
\cline { 2 - 5 } & No. & $\%$ & No. & $\%$ \\
\hline Yes & 10 & 20.00 & 18 & 36.00 \\
\hline No & 40 & 80.00 & 32 & 64.00 \\
\hline Total & 50 & 100.00 & 50 & 100.00 \\
\hline
\end{tabular}

Chi square $=4.023 ; \mathrm{P}=0.031$

\section{DISCUSSION}

Of the 100 patients who were randomized, $50(100.00 \%)$ women's were included in study group with completed follow up and $50(100.00 \%)$ women's in control group.

In the present study, majority of the patients were in the age group 21 to 25 years the distribution was comparable in both the groups $(50.00 \%$ vs. $60.00 \%)$. The mean age in study group was $25.1 \pm 3.77$ years whereas in control group it was $24.1 \pm 2.93$ years $(\mathrm{P}=0.030)$.

In this study, the number of primigravida and multigravida were almost equal in both the groups and thus they were both comparable.

In this study, $12.00 \%$ of the women had gestational age between 28 to 31.6 weeks, $22.00 \%$ in gestational age 32 to 33.6 weeks and $66.00 \%$ in gestational age 34 to 36.6 weeks each, at the time of enrollment in study group. In control group $50.00 \%$ had gestational age between 34 to 36.6 weeks followed by $28.00 \%$ with gestational age between 32 to 33.6 weeks and $22.00 \%$ with 28 to 31.6 weeks. The gestational age at enrollment was comparable in both the groups $(\mathrm{P}=0.231)$.

In the present study, in study group majority of the women $52.00 \%$ delivered between 37 to 40 weeks of gestation as compared to $30.00 \%$ in control group. Most of the women in control group $42.00 \%$ delivered between 34 to 36.6 weeks. The mean period of gestation at delivery was significantly high in study group $37.51 \pm$ 2.70 vs. $35.15 \pm 2.72$ as $\mathrm{P}<0.05$ compared to control group.

In the present study the recurrence of preterm labor was significantly high in the control group, as $68.00 \%$ of the mothers delivered before 37 weeks compared to only $44.00 \%$ mothers in study group as $\mathrm{P}<0.05$. This was statistically significant, suggesting that there was a reduction in the recurrence rate of preterm labor in the study group compared to the control group.

In the present study maximum latency period beyond 42 days was noted in study group with the majority of women $22.00 \%$ having a latency period between 36 to 42 days where as in control group, maximum latency period 
was within 35 days with more than half $50.00 \%$ of the women having a latency period of less than 7 days. The mean latency period in study group was significantly higher than that of control group $(26.38 \pm 15.47$ vs. 11.74 \pm 9.25 days, $\mathrm{P}<0.05)$. This difference between both the groups was statistically significant $\mathrm{p}<0.05$, suggesting that the latency period was longer in the group of pregnant women treated with progesterone maintenance therapy as compared to the control group.

In the present study, 21 babies $(42.00 \%)$ in study group had birth weight more than $2.5 \mathrm{~kg}$ compared to significantly less number of babies i.e. 12 babies $(24.00 \%)$ in control group $(\mathrm{P} \leq 0.05)$. The mean birth weight of babies in study group $2.39 \pm 0.44 \mathrm{~kg}$ was significantly higher than that in control group $2.20 \pm 0.49$ $\mathrm{kg}$.

In the present study only 10 babies $(20.00 \%)$ from study group were admitted in NICU whereas in control group $18(36.00 \%)$ babies were admitted in NICU. This difference was statistically significant as $\mathrm{P}<0.05$, suggesting that significantly less number of NICU admission were noted in study group compared to control group ( $20.00 \%$ vs. $36.00 \%$; $\mathrm{P}=0.031$ ).

Preterm labor complicates 5-10\% of pregnancies and is a leading cause of neonatal morbidity and mortality worldwide. The effectiveness of tocolytics in patients with preterm labor, to stop uterine contractions (acute tocolysis) or maintain quiescence (maintenance therapy) has been reviewed in the past. Use of tocolytics in patients with preterm labor, may help in prolonging pregnancy, and thereby reduce the incidence of preterm labor and perinatal morbidity. Many drugs have been used for this purpose viz. nifidipine, magnesium sulphate, beta-mimmetics, indomethacin, atosiban, isoxuprine hydrochloride etc. most of these drugs have been further tested for maintenance tocolysis. However, long term use of these drugs was observed to have adverse effects and reduced efficacy, due to which they are not recommended for maintenance tocolysis. On the other hand, progesterone has long been considered as an important agent in the maintenance of uterine quiescence and has been used extensively in primary and secondary prevention of preterm delivery. Hence, the present study was undertaken to determine whether maintenance tocolytic therapy with vaginal micronized progesterone $(400 \mathrm{mg})$ therapy upto 37 weeks of gestation in patients with arrested preterm labor prolongs the latency period.

This study was a randomized controlled trial conducted in the department of obstetrics and gynaecology, AVBRH Sawangi, Wardha. A total of 100 pregnant women fulfilling the inclusion criteria were included in this study. Based on computer generated random numbers, these women were randomized into two groups of 50 each, namely study group (Group s) which received 400 $\mathrm{mg}$ of vaginal micronized progesterone and control group (Group C) which did not receive any drug.
Of the 100 patients who were randomized, 50 (100.00\%) women's were included in study group with completed follow up and $50(100.00 \%)$ women's in control group.

In the present study, majority of the patients were in the age group 21 to 25 years the distribution was comparable in both the groups $(50.00 \%$ vs. $60.00 \%)$. The mean age in study group was $25.1 \pm 3.77$ years whereas in control group it was $24.1 \pm 2.93$ years $(\mathrm{P}=0.030)$.

In this study, the number of primigravida and multigravida were almost equal in both the groups and thus they were both comparable.

In this study, $12.00 \%$ of the women had gestational age between 28 to 31.6 weeks, $22.00 \%$ in gestational age 32 to 33.6 weeks and $66.00 \%$ in gestational age 34 to 36.6 weeks each, at the time of enrollment in study group. In control group $50.00 \%$ had gestational age between 34 to 36.6 weeks followed by $28.00 \%$ with gestational age between 32 to 33.6 weeks and $22.00 \%$ with 28 to 31.6 weeks. The gestational age at enrollment was comparable in both the groups $(\mathrm{P}=0.231)$.

In the present study, in study group majority of the women $52.00 \%$ delivered between 37 to 40 weeks of gestation as compared to $30.00 \%$ in control group. Most of the women in control group $42.00 \%$ delivered between 34 to 36.6 weeks. The mean period of gestation at delivery was significantly high in study group $37.51 \pm$ 2.70 vs. $35.15 \pm 2.72$ as $\mathrm{P}<0.05$ compared to control group.

In the present study the recurrence of preterm labor was significantly high in the control group, as $68.00 \%$ of the mothers delivered before 37 weeks compared to only $44.00 \%$ mothers in study group as $\mathrm{P}<0.05$. This was statistically significant, suggesting that there was a reduction in the recurrence rate of preterm labor in the study group compared to the control group.

In the present study maximum latency period beyond 42 days was noted in study group with the majority of women $22.00 \%$ having a latency period between 36 to 42 days where as in control group, maximum latency period was within 35 days with more than half $50.00 \%$ of the women having a latency period of less than 7 days. The mean latency period in study group was significantly higher than that of control group $(26.38 \pm 15.47$ vs. 11.74 \pm 9.25 days, $\mathrm{P}<0.05)$. This difference between both the groups was statistically significant $\mathrm{p}<0.05$, suggesting that the latency period was longer in the group of pregnant women treated with progesterone maintenance therapy as compared to the control group.

In the present study, 21 babies $(42.00 \%)$ in study group had birth weight more than $2.5 \mathrm{~kg}$ compared to significantly less number of babies i.e. 12 babies $(24.00 \%)$ in control group $(\mathrm{P}<0.05)$. The mean birth weight of babies in study group $2.39 \pm 0.44 \mathrm{~kg}$ was 
significantly higher than that in control group $2.20 \pm 0.49$ $\mathrm{kg}$.

In the present study only 10 babies $(20.00 \%)$ from study group were admitted in NICU whereas in control group $18(36.00 \%)$ babies were admitted in NICU. This difference was statistically significant as $\mathrm{P}<0.05$, suggesting that significantly less number of NICU admission were noted in study group compared to control group $(20.00 \%$ vs. $36.00 \%$; $\mathrm{P}=0.031)$.

\section{CONCLUSION}

We conclude that, maintenance tocolytic therapy with micronised progesterone (400 mg) up-to 37 weeks of gestation in patients with arrested preterm labor significantly prolongs the latency period $(26.38 \pm 15.47)$. It significantly reduces the rate of recurrence of preterm labor $(68 \%$ in control group vs. $44 \%$ in study group, $p$ value, <0.05). It also results in better perinatal outcome by improving the birth weight $(2.39 \pm 0.44$ in study group vs. $2.20 \pm 0.49$ in control group, $\mathrm{P}<0.05)$ and reducing the need for NICU admissions (20\% in study group vs. $36 \%$ in control group, $\mathrm{P}$ value $<0.05)$.

\section{Funding: No funding sources}

Conflict of interest: None declared

Ethical approval: The study was approved by the institutional ethics committee

\section{REFERENCES}

1. Steer P. The epidemiology of preterm labor. BJOG. 2005;112(Suppl 1):1-3.

2. Goldenberg RL. The management of preterm labor. Obstet Gynaecol. 2002;100(5 pt.1):1020-37.

3. Dodd JM, Crowther CA. The role of progesterone in prevention of preterm birth. Int $\mathrm{J}$ Womens Health. 2009;1:73-84.

4. H. Blencowe, Simon Cousens, Doris Chou, Mikkd Ostergaard. Born too soon: the global epidemiology of 15 million preterm birth. Reprod Health. 2013;10(Suppl):s2.
5. Chnandraharan E, Arulkumaran S. Recent advances in management of preterm labor. J Obstet Gynaecol India. 2005;55(2):118-24.

6. Borna S, Sahabi N. Progesterone for maintenance tocolytic therapy after threatened preterm labour: a randomised controlled trial. Aust N Z J Obstet Gynaecol. 2008;48(1):58-63.

7. Vause S, Johnston T. Management of preterm labour. Arch Dis Child Fetal Neonat Ed. 2000 Sep;83(2):F75-85.

8. de heus R, Mulder EJ, Visser GH. Management of preterm labor: atosiban or nifedipine? Int J Womens Health. 2010;2:137-42.

9. Raman Wilms L, Tseng AL, Wighdart S, Emarson TR, Korean G. Fetal genital effect of $1^{\text {st }}$ trimester sex hormone exposure a meta-analysis. Obstet Gynaecol. 1995;85:141-9.

10. S Chardein JL. Congenital abnormalities and hormones during pregnancy clinical review. Teratology. 1980;22:251-70.

11. Blencowe H, Cousens S, Oestergaard M, Chou D, Moller AB, N Arwarl R, et al. National Regional and worldwide estimates of preterm birth. Lancet. 2012. Jun;379(9832):2162-72.

12. Bowen R. Placental hormones, 2000. Available at: http://www.vivo.colostate.edu/hbooks/pathphys/repr od/placenta/endocrine.html. Accessed 12 March 2008.

13. Vaja Pradyuman, Goyal Mekhla. A comparative study of two tocolytic agents for inhibition of preterm labour. Gujarat Medical J. 2014 Mar;69(1):28-31.

14. Singh Nisha, Singh Uma, Seth Shikha. Comparative study of nifedipine and isoxuprine as tocolytics for preterm labor. J Obstet Gynaecol India. 2011 SepOct;61(5):512-5.

15. Saifon Chawanpaiboon, Sujin Kanokpongsakdi. Preterm birth at Siriraj hospital: a 9-year period review (2002-2010). Thailand Siriraj Med J. 2011;63:143-6.

DOI: $10.5455 / 2320-1770$. ijrcog20141234

Cite this article as: Mishra GS, Inamdar SA. Role of micronised progesterone in maintenance therapy following arrested preterm labor: a randomised controlled trial. Int J Reprod Contracept Obstet Gynecol 2014;3:1050-5. 